\title{
IncRNA Malat1 modulates the maturation process, cytokine secretion and apoptosis in airway epithelial cell-conditioned dendritic cells
}

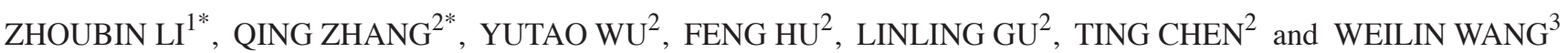 \\ Departments of ${ }^{1}$ Lung Transplantation and ${ }^{2}$ Cardiology; ${ }^{3}$ Key Laboratory of Precision Diagnosis and Treatment for \\ Hepatobiliary and Pancreatic Tumor of Zhejiang Province, Division of Hepatobiliary and Pancreatic Surgery, \\ First Affiliated Hospital, School of Medicine, Zhejiang University, Hangzhou, Zhejiang 310003, P.R. China
}

Received March 25, 2018; Accepted August 24, 2018

DOI: $10.3892 /$ etm.2018.6687

\begin{abstract}
Airway epithelial cells (AECs) are the first point of contact with airborne antigens and are able to instruct resident immune cells to appropriate immune responses. Previous studies have shown that the abnormal expression of metastasis-associated lung adenocarcinoma transcript 1 (Malat1) was associated with tumorigenesis, progression, metastasis, and apoptosis in many cancer types. However, little is known about its functional involvement in the cross-talk of AECs with dendritic cells (DCs). The aim of the present study was to identify Malat1 as a novel epithelial cell-derived immune-modulating factor that contributes to the specific inflammatory-immune airway microenvironment. By using an in vitro co-culture model, where layers of AECs can interact with DCs, and transfecting Malat1 siRNA in AECs, AEC-conditioned DCs were harvested for further analysis of the celluar phenotype, secretion of inflammatory chemokines,
\end{abstract}

Correspondence to: Dr Weilin Wang, Key Laboratory of Precision Diagnosis and Treatment for Hepatobiliary and Pancreatic Tumor of Zhejiang Province, Division of Hepatobiliary and Pancreatic Surgery, First Affiliated Hospital, School of Medicine, Zhejiang University, 79th Qingchun Road, Hangzhou, Zhejiang 310003, P.R. China E-mail:wam@zju.edu.cn

Dr Ting Chen, Department of Cardiology, First Affiliated Hospital, School of Medicine, Zhejiang University, 79th Qingchun Road, Hangzhou, Zhejiang 310003, P.R. China

E-mail: ct010151452@zju.edu.cn

${ }^{*}$ Contributed equally

Abbreviations: lncRNA, long non-coding RNA; DCs, dendritic cells; AECs, airway epithelial cells; miRNA, microRNA; siRNA, small interfering RNA; Malat1, metastasis-associated lung adenocarcinoma transcript 1; MLE-12, murine type II alveolar epithelial cells; BMDCs, bone marrow-derived dendritic cells

Key words: lncRNA, Malat1, dendritic cell, airway epithelial cells, co-cultured and expression of apoptotic markers. The present study clearly demonstrated that Malat1 modulates the maturation process, pro-inflammatory cytokine secretion and apoptosis in AECs-conditioned DCs.

\section{Introduction}

The human lung exchanges thousands of liters of air daily and is often exposed to different stimuli, such as airborne allergens, viruses, and bacteria (1). The presence of certain special respiratory microenvironments controls and limits the inflammatory response (2-6). Airway epithelial cells (AECs) represent the mechanical immune barrier to the external environment. These cells cover the airway surface and serve as the frontline of defense against inhalable contamination. Respiratory epithelial cells, which is an essential part of the innate immune system, are also responsible for the initial immuno-inflammatory response. Among these different subtypes of AECs, type II AECs play a critical role in the induction of cellular innate immune response $(7,8)$.

In recent years, epithelial cells have been established to play complex roles in organ-specific immunity. After antigen recognition, AECs determine the functional characteristics of innate immune cells through a soluble or contact-dependent mechanism. Several studies $(9,10)$ demonstrated that respiratory epithelial cells could inhibit lipopolysaccharide (LPS)-stimulated dendritic cells (DCs) from secreting proinflammatory cytokine by inducing macrophage-derived chemokines and even immune-stimulatory DCs $(11,12)$. Studies have also shown that via a constitutive release mediator, epithelial cells could regulate mucosal DCs as well as induce inflammatory response in DCs (13).

DCs as the strongest antigen-presenting cells, are the only cells that can activate naive immune cells and participate in recognizing and presenting antigen-initiated immune response. Epithelial modulation may also be involved in the induction or production of some special DCs, such induction can result in the dysfunction of T cells (14). Therefore, developing and validating the effective in vitro model system that establishes the crosstalk between different epithelial cells and DCs will contribute to respiratory and immunology research. 
Long noncoding RNAs (lncRNAs) are a class of RNA molecules with transcript lengths greater than $200 \mathrm{nt}$. Initially, they were considered as the 'noise' of genomic transcription without biological functions. However, growing evidence suggests that lncRNAs are an important regulator of biological processes such as X-chromosome inactivation, modulation of protein activity and chromatin remodeling $(15,16)$. Their potential importance in regulating immune responses, particularly, in the innate immune response, has only been discovered recently (17-20). Metastasis-associated lung adenocarcinoma transcript 1 (Malat1) is a $7 \mathrm{~kb}$ nuclear long non-coding RNA located at chromosome 11q13. Malat1 has been found to be a predictive biomarker of early metastasis of non-small cell lung cancer. Previous studies have shown that abnormal expression of Malat1 was associated with tumorigenesis, progression, metastasis, and apoptosis in many cancer types (21-32). Besides its oncogenic role, Malat1 is involved in many other diseases as well as in normal physiological processes, such as vascular growth, synaptogenesis, and muscle cell generation $(33,34)$. However, knowledge about the direct crosstalk between this lncRNA and DCs remain largely unknown.

In the present study, by knocking down the expression of Malat1 in AECs and by using the in-vitro co-culture model, where cell layer of AECs can interact with DCs, we harvest AEC-conditioned DCs for further analysis of the cellular phenotype, secretion of inflammatory chemokines, and expression of apoptotic markers. Therefore, this study aims to explore the relationship between Malat1, AECs, and DCs, also intends to identify Malatl as a novel epithelial cell-derived immunomodulatory factor for specific immuno-inflammatory microenvironment. Our results suggest that the Malat1-mediated crosstalk between epithelial cells and DCs can alter the phenotype and function of DCs.

\section{Materials and methods}

AECs culture and transfection. Murine type II alveolar epithelial cells (MLE-12) were isolated from female C57BL/6 mice (purchased from the Shanghai Institutes for Biological Sciences Shanghai, China) as described by Corti et al (35). siRNA control and siRNA Malat1 were obtained from Ribo (cat. no. stQ0019997-1; siR-Ribo, lnc., Guangzhou, China). Transfection reagent Lipofectamine 3000 reagent (cat. no. L3000-015; Invitrogen; Thermo Fisher Scientific, Inc. Waltham, MA, USA) and transfection media opti-MEM (cat. no. 31985062; Gibco; Thermo Fisher Scientific, Inc.) were purchased from Thermo Fisher Scientific, Inc. MLE-12 cells were seeded at $1 \times 10^{4} / \mathrm{cm}^{2}$ one day before transfection to reach $60-70 \%$ density the next day. For one well of 6-well plate, medium was changed to $1 \mathrm{ml}$ empty medium without antibiotics or fetal bovine serum (FBS; cat. no. 10099141; Gibco; Thermo Fisher Scientific, Inc.) approximately $20 \mathrm{~min}$ before the transfection. In final experiments, mix A $(50 \mu 1$ opti-MEM/well+ $0.5 \mu \mathrm{l}$ siRNA/well) and mix B (50 $\mu 1$ opti-MEM/well+2 $\mu$ l RNAi Max/well) was prepared. The final concentration of siRNA was $50 \mathrm{nM}$.

Bone marrow-derived DCs (BMDCs). BMDCs were generated from C57BL/6 mice as previously described (36). All animal experiments were performed according to protocols approved by the Institutional Committee for Use and Care of Laboratory Animals. In brief, femurs and tibia of mice were resected and washed with phosphate buffered saline (PBS; GNM-20012; GENOM., Ltd., Hangzhou, Zhejiang, China) to obtain bone marrow cells. After incubation with $\mathrm{NH} 4 \mathrm{Cl}$ lysing buffer to remove red blood cell (RBC), bone marrow cells were placed in 6-well plates in RPMI-1640 (GNM-31800; GENOM., Ltd.). The cell layer was then gently washed by medium $2 \mathrm{~h}$ later to remove non-adhering cells. Adherent cells were incubated in the complete media (RPMI-1640 containing 2 mM L-glutamine (cat. no. 1294808-100MG; Sigma-Aldrich; Merck KGaA, Darmstadt, Germany) supplemented with $10 \%$ FBS, $1 \%$ of nonessential amino acids (cat. no. 11140050; Gibco; Thermo Fisher Scientific, Inc.), $1 \%$ of sodium pyruvate, $20 \mathrm{ng} / \mathrm{ml} \mathrm{rmGM-CSF}$ (cat. no. 415-ML-010/CF) and $10 \mathrm{ng} / \mathrm{ml}$ rmIL-4 (cat. no. 404-ML-010/CF; both R\&D Systems, Inc., Minneapolis, MN, USA) for 6 days. Medium was changed every 2 days. On the sixth day, floating adherent cells were collected and used as BMDCs. To induce DCs mature, cells were stimulated with $100 \mathrm{ng} / \mathrm{ml}$ LPS (Escherichia coli 055B5; Sigma-Aldrich; Merck KGaA).

Co-culture model system. The AECs-DCs co-culture model was established as described before (37). In brief, the Malat1 treated MLE-12 cells were incubated for $48 \mathrm{~h}$ before cultured on the top of the inverted filter inserts, which were made of polyethylene terephthalate (cat. no. 353092; BD Pharmingen; Franklin Lakes, USA) with pore size of $3 \mu \mathrm{m}$, The filters were then reverted and placed into wells with RPMI-based culture media, and DCs suspended in RPMI-based culture media were added to the basal side within the insert well. DCs were harvest after $72 \mathrm{~h}$.

$R N A$ extraction and reverse transcription-quantitative polymerase chain reaction $(R T-q P C R)$. Total RNA was extracted using TRIzol (cat. no. 12183555; Invitrogen; Thermo Fisher Scientific, Inc.) and then reversely transcribed into first-strand cDNA using PrimeScript RT reagent kit with gDNA Eraser (cat. no. RR047A; Takara Biomedical Technology Co., Ltd., Beijing, China) according to manufacturers' instructions. Real-time PCR was performed with Takara premix Ex Taq II (cat. no. DRR820A; Takara Biomedical Technology Co., Ltd.) and was run on CFX96TM Real-Time System (cat. no. 1855195.; Bio-Rad Laboratories, Inc., Hercules, CA, USA) in a total volume of $10 \mu \mathrm{l}$ containing $5 \mathrm{ul}$ Takara premix Ex Taq II and 5 ng cDNA template. The PCR thermal cycle parameters were as follows: $2 \mathrm{~min}$ at $50^{\circ} \mathrm{C}, 30 \mathrm{sec}$ at $95^{\circ} \mathrm{C}$ and 40 cycles of $95^{\circ} \mathrm{C}$ for $5 \mathrm{sec}$ and $60^{\circ} \mathrm{C}$ for $34 \mathrm{sec}$. Expression of mRNA was normalized to the expression of mouse GAPDH (mGAPDH) and quantified using the $2^{-\Delta \Delta \mathrm{Cq}}$ method (38). Primer pairs for qPCR are listed as follows: mmu F-malat1, 5'GGGCATTTCC ATTCCTCTC 3' and mmu R-malat1, 5'GTCTCTACGGGCAC ATTAC 3'; mmuF-CD80, 5'ACCCCCAACATAACTGAGTC T3' and mmuR-CD80, 5'TTCCAACCAAGAGAAGCGAGG3'; mmuF-CD86, 5'TGTTTCCGTGGAGACGCAAG3' and mmuR-CD86， 5'TTGAGCCTTTGTAAATGGGCA3'; mmuF-IL4, 5'GTTGTCATCCTGCTCTTC3' and mmuR-IL4, 5'GTTTGGCACATCCATCTC3'; mmuF-IL6, 5'TGGAGCCC ACCAAGAACGATAG3' and mmuR-IL6, 5'TGTCACCAGCA TCAGTCCCAAG3'; mmuF-INF- $\gamma, 5$ 'TCAAGTGGCATAGAT GTG3' and mmuR-INF- $\gamma$, 5'TGTTGCTGAAGAAGGTAG3'; 
mmuF-CCL2, 5'TTAAAAACCTGGATCGGAACCAA3' and mmuR-CCL2, 5'GCATTAGCTTCAGATTTACGGGT3'; mmuF-CCL5, 5'GCTGCTTTGCCTACCTCTCC3' and mmuR-CCL5, 5'TCGAGTGACAAACACGACTGC3'; mmuF-CXCR4, 5'GACTGGCATAGTCGGCAATG3' and mmuR-CXCR4, 5'AGAAGGGGAGTGTGATGACAAA3'; mmuF-CXCR2, 5'ATGCCCTCTATTCTGCCAGAT3' and mmuR-CXCR2, 5'GTGCTCCGGTTGTATAAGATGAC3'; mmuF-GAPDH, 5'CTGCCCAGAACATCATCC3' and mmuR-GAPDH, 5'CTCAGATGCCTGCTTCAC3'.

Transwell chemotaxis assay. Migration chemotaxis assay was performed by applying 24-well Boyden chambers with $8 \mu \mathrm{m}$ pore size polycarbonate membranes (cat. no. 662638; Greiner Bio-One, Ltd., Frickenhausen, Germany) as described previously. After co-culturing with MEL-12 cells transfected with siRNA control or Malat1 siRNA, DC were seeded onto the upper chamber at $1 \times 10^{5}$ cells. The bottom chamber contained $600 \mu 110 \% \mathrm{FBS}$ medium with or without $200 \mathrm{ng} / \mathrm{ml}$ Chemokine ligand 19 (CCL19). After incubation for $6 \mathrm{~h}$ at $37^{\circ} \mathrm{C}$, the cells remained on the upper side of the filters were removed by a cotton swab. The migrated cells on the underside of the membrane were fixed with $4 \%$ paraformaldehyde (PFA) prior to staining with $0.1 \%$ crystal violet solution for $15 \mathrm{~min}$.

Flow cytometry. DCs were co-cultured for $6 \mathrm{~h}$ with MLE-12 cells interfered with siRNA control or Malat1 siRNA, followed by stimulation with LPS and further incubation for $72 \mathrm{~h}$. DCs were detached from the flasks by trypsin (GNM-15050; GENOM., Ltd.), and cell numbers were counted. Cells were then fixed with $4 \%$ paraformaldehyde for $15 \mathrm{~min}$ at room temperature. After washing with PBS, cells were re-suspended in 5\% swine serum and blocked with Fc Receptor Blocking Solution (cat. no. 422301; Biolegend, Inc., San Diego, CA, USA) for $5 \mathrm{~min}$. Aliquots of about $2 \times 10^{5}$ cells were then incubated with specific antibodies (mouse CD80; cat. no. 561954), CD86 (cat. no. 561962; both BD Biosciences, Franklin Lakes, NJ, USA), MHC-II (cat. no. bs-4107R; Bioss Antibodies, Inc., Woburn, MA, USA), Annexin-V-FITC antibody (cat. no. 70-AP101-100; Multiscience, Hangzhou, Zhejiang, China) and $\mathrm{IgG}$ control for $1 \mathrm{~h}$ at $4^{\circ} \mathrm{C}$. Cells were then washed three times and analyzed with the flow cytometer (BD FACS Canto $^{\mathrm{TM}}$ II system). Further analysis was done with Flow Jo. Gating set as less than $1 \%$ of marker expression in $\mathrm{IgG}$ control group.

ELISA assays of cytokine. DCs were co-cultured with siRNA control or Malat1 siRNA interfered MLE-12 for $6 \mathrm{~h}$, LPS was added and the cells were incubated for another $72 \mathrm{~h}$. To detect the secretion of tumor necrosis factor- $\alpha$ (TNF- $\alpha$ ), IL-4, INF-r and IL-6, the cell supernatant was harvest and analyzed by Sandwich Enzyme Immunoassay kits (R\&D Systems Europe Ltd., Abingdon, UK) according to the manufacturer's protocol.

Methylthiazolyltetrazolium (MTT) assay. DCs were co-cultured with siRNA control or Malat1 siRNA interfered MLE-12 for $6 \mathrm{~h}$, followed by stimulation with LPS and further incubation for 72 h. MTT (cat. no. c0009; Beyotime Institute of Biotechnology, Shanghai, China) of $0.5 \mathrm{mg} / \mathrm{ml}$ were then added to each well. After $4 \mathrm{~h}$ of incubation at $37^{\circ} \mathrm{C}$, cells were treated with $1 \mathrm{ml}$ of dimethyl sulfoxide (cat. no. D2650-5*5ML; Sigma-Aldrich; Merck KGaA) followed by incubation at $37^{\circ} \mathrm{C}$ overnight. Finally, optical densities were measured at $570 \mathrm{~nm}$, and the growth inhibitory rate was calculated.

Immunoblotting. 10-50 $\mu \mathrm{g}$ of the protein was mixed with a $1 / 4$ volume of the boiled 5X SDS loading buffer (cat. no. p0015) and then adjusted to the same volume with $1 \mathrm{X}$ SDS loading buffer (cat. no. P0015A; both Beyotime Institute of Biotechnology). The mix was then boiled at $95^{\circ} \mathrm{C}$ for 10 min before loaded to the NuPage 4-12\% Tris-Glycine gel (cat. no. EC60249BOX) immersed in NuPage MOPS SDS running buffer (cat. no. NP0001; both Invitrogen; Thermo Fisher Scientific, Inc.) in a XCell SureLock Mini-Cell (cat. no. NP0335BOX; Thermo Fisher Scientific, Inc.). The gel was run at $160 \mathrm{~V}$ for about $75 \mathrm{~min}$ until the marker with lowest molecular weight was at the bottom of the gel. Protein was then transferred from the gel to the membrane in $1 \mathrm{X}$ transfer buffer for $45 \mathrm{~min}$. The membrane was then blocked with 5\% milk in PBS-Tween and incubated with primary antibody diluted in $5 \%$ milk at $4^{\circ} \mathrm{C}$ overnight. After being washed with PBS-Tween for three times with 10 min each, the membrane was incubated with secondary antibody for $1 \mathrm{~h}$ at room temperature. Secondary antibodies were HRP-conjugated and purchased from Dako (Polyclonal Rabbit anti-goat, cat. no. 103P0449; Polyclonal Rabbit anti-mouse, cat. no. P0260; Polyclonal Swine anti-rabbit, cat. no. P0217; Dako; Agilent Technologies, Inc., Santa Clara, CA, USA). Further 3 washes were performed before addition of ECL detection solutions. After incubation with the detection solution for $2 \mathrm{~min}$, exposure of the films was carried out with the Compact X4 in the dark room. The bound primary antibodies: Rabbit-anti-mouse-caspase-3 (Ab44976), anti-mouse-Bax (Sc-493), anti-rabbit-Bcl2 (Sc-492), anti-mouse-GAPDH (CST-5174) diluted 1:1,000 in PBST.

Statistical analysis. Data between two groups with normal distribution were analyzed with unpaired and ungrouped t-tests, and data not normally distributed were analyzed with unpaired and nonparametric Mann-Whitney U test. Data across multiple groups were analyzed with one-way ANOVA test, followed by Bonferroni post-hoc analysis if $\mathrm{P}<0.05$. Data were shown as the mean \pm standard error of mean (SEM) and graphs were generated using GraphPad Prism 6 software. $\mathrm{P}<0.05$ was considered to indicate a statistically significant difference $\left({ }^{*} \mathrm{P}<0.05 ;{ }^{* *} \mathrm{P}<0.01\right.$ and $\left.{ }^{* * *} \mathrm{P}<0.001\right)$.

\section{Results}

Expression of Malatl in AECs-DCs co-culture system. The tracheal epithelial cells have been found to regulate the gene expression in BMDCs (39), but whether these respiratory epithelial cell could modulate the long-non coding RNA expression is unclear. To contact the DCs with alveolar epithelial cells (MLE-12), MLE-12 cells were cultured on top of inverted filter inserts. The filters were then reverted and placed into wells containing RPMI-1640 media. The DCs stimulated with or without LPS were suspended in media and added to the basal side of the insert well (Fig. 1A), We term this system as AECs-conditioned DCs system. After $48 \mathrm{~h}$, the expression of Malat1 in AECs was detected. The Malat1 expression was significantly enhanced in this co-culture system regardless of 
LPS addition (Fig. 1B and C). Furthermore, to elucidate the regulatory role of Malat1 in AECs-conditioned DCs, we used a chemically synthesized Malat1 inhibitor (Malat1 siRNA) to suppress the Malat1 expression. Fig. 1D revealed the significant diminution of Malat1 expression after the Malat1 knockdown in MLE-12 cells.

Effects of Malat1 on the maturation of AECs-conditioned DCs. Immature DCs can assimilate antigens efficiently but express low levels of costimulatory molecules. Upon maturation, DCs dramatically augment their ability to stimulate naive $\mathrm{T}$ cells through the surface exposure of antigen-MHC complexes and increased expression of costimulatory molecule. Following co-culture for $48 \mathrm{~h}$ with AECs that had been treated with Malat1 silencing, the DCs were harvested to detect the specific maturity surface marker by real-time PCR and FACS. Our results showed that some surface molecules (CD80, CD86, and MHCII) of the AECs-conditioned DCs were upregulated in response to incubation with Malat1 inhibitor, both at the protein (Fig. 2A-F) and mRNA levels (Fig. 2G), implying Malat1 can partly induce the maturation of DCs cultured in AECs-conditioned system.

AECs-conditioned DCs cytokine secretion in response to Malat1. The cytokine secreted by DCs plays a vital role during $\mathrm{T}$ cell polarization. To investigate the functional role of Malat1 in AECs-conditioned DCs, levels of certain inflammatory cytokines were analyzed. The Malat1 inhibitor increased the secretion of some inflammatory cytokines by DCs such as TNF-alpha, IL-6, and IFN- $\gamma$ significantly (more than 3-5 fold at the RNA level and approximately 2 fold at the protein level) (Fig. 3). By contrast, IL-4 expression was slightly downregulated by Malat1 inhibitor (50\% off) (Fig. 3). These results indicated that Malatl could affect the inflammatory response of AECs-conditioned DCs.

Chemokine production of AECs-conditioned DCs in response to Malat1. We also detected the expression of chemokines in the AECs-conditioned DCs. The Malat1 siRNA dramatically increased the secretion of chemokines, such as CXCR2 and CXCR4, in AECs-conditioned DCs, both at the mRNA and protein levels (Fig. 4A-D). Given that Malat1 siRNA-treated MLE-12 significantly increased the chemokine expression of DCs, we further performed Transwell assay to confirm the effect of Malat1 on the chemotaxis of co-cultured DCs. As expected, the Malat1 siRNA-treated MLE-12 also remarkably induced DC chemotaxis (Fig. 4E). All these results suggested that Malat1 could affect the chemokine secretion and chemotaxis of AECs-conditioned DCs.

Malat1 knockdown attenuates the apoptosis of AECs-conditioned DCs. To explore the effect of Malat1 knockdown on the apoptosis of AECs-conditioned DCs, the apoptosis marker Annexin V in the DCs was detected by flow cytometry. Compared with siRNA control group, the mean apoptotic cell fractions (early apoptotic + late apoptotic) were significantly decreased, and viable cell populations were significantly decreased upon Malat1 inhibition ( $\mathrm{P}=0.04)$ (Fig. 5A-D). Expression of apoptotic markers, such as caspase-3, Bax, and $\mathrm{Bcl} 2$, in the co-cultured DCs was decreased after transfection with Malat1 siRNA (Fig. 5E). Meanwhile, we detected the
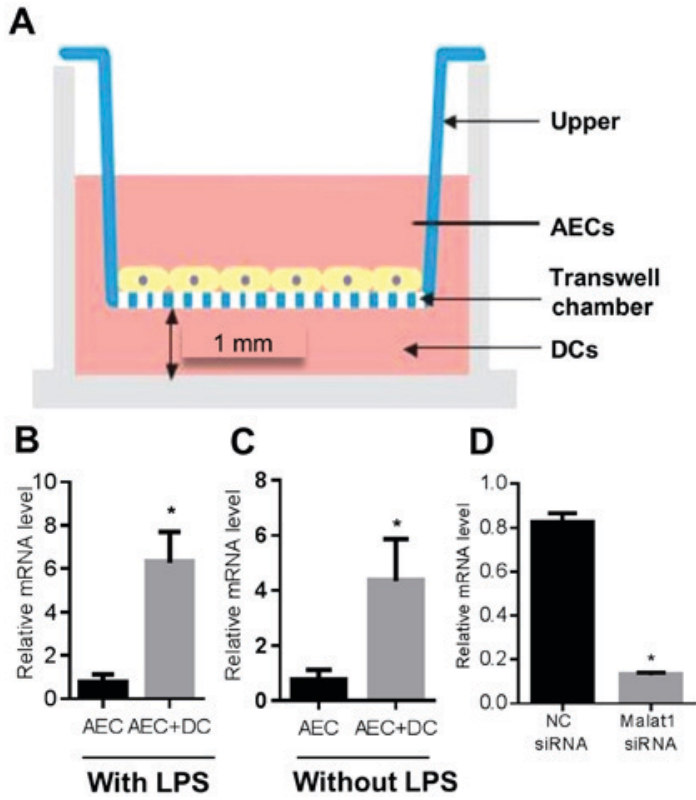

Figure 1. Malat1 is implicated in AEC upon DC co-culture. (A) Simple summary of the co-culture system. The expression of Malat1 in AECs was detected by real-time PCR and found to be upregulated in the co-culture system in the presence (B) and absence (C) of LPS. (D) Malat1 knockdown AEC was generated by siRNA transfection, then the transfected AECs were harvested and subjected to q-PCR ( $\mathrm{n}=5,{ }^{*} \mathrm{P}<0.05$ vs. AEC only group group and ' $\mathrm{NC}$ siRNA'). AEC, airway epithelial cells; DC, dendritic cell; Malat1, metastasis-associated lung adenocarcinoma transcript 1 ; q-PCR, quantitative polymerase chain reaction; LPS, lipopolysaccharide.

effect of Malat1 on the viability of AECs-conditioned DCs by using MTT assay, Our results found that the Malat1 siRNA slightly induced cell viability $(18.2 \pm 1.3 \%)$ as compared to the control group at $72 \mathrm{~h}$ (Fig. 5F), indicating an apoptotic-inducing role of Malat1 in AECs-conditioned DCs.

\section{Discussion}

Mucosal epithelial cells usually induce a specific microenvironment to regulate the intensity of classical immune responses (3). Given their frequent contact with inhaled antigens or microbial substances, immunomodulatory functions appear particularly important in the trachea (40). Previous study (39) have revealed the interrelationship between epithelial cells and DCs at the transcriptional level. In this study, we provide the first evidence that Malat1 can modulate the maturation process, pro-inflammatory cytokine secretion and apoptosis in AECs-conditioned DCs as Schematic representation in Fig. 6.

Recent studies (41-46) showed that lncRNAs were expressed in a highly lineage-specific manner with the role of regulating differentiation and physiological functions of innate and acquired cell types (47). Specific lncRNAs have been identified to regulate the differentiation of DCs and to inhibit their ability to stimulate $\mathrm{T}$ cells by activating the transcription factor STAT3. However, IncRNAs that could potentially interact with DCs and AECs have not been found. In our study, significant upregulation of Malat1 in AECs was observed when co-cultured with DCs, suggesting potential involvement of Malat1 in the interaction between AECs and DCs.

We also observed that CD80, CD86, and MHCII were upregulated in DCs after co-culturing with the Malat1-inhibited 

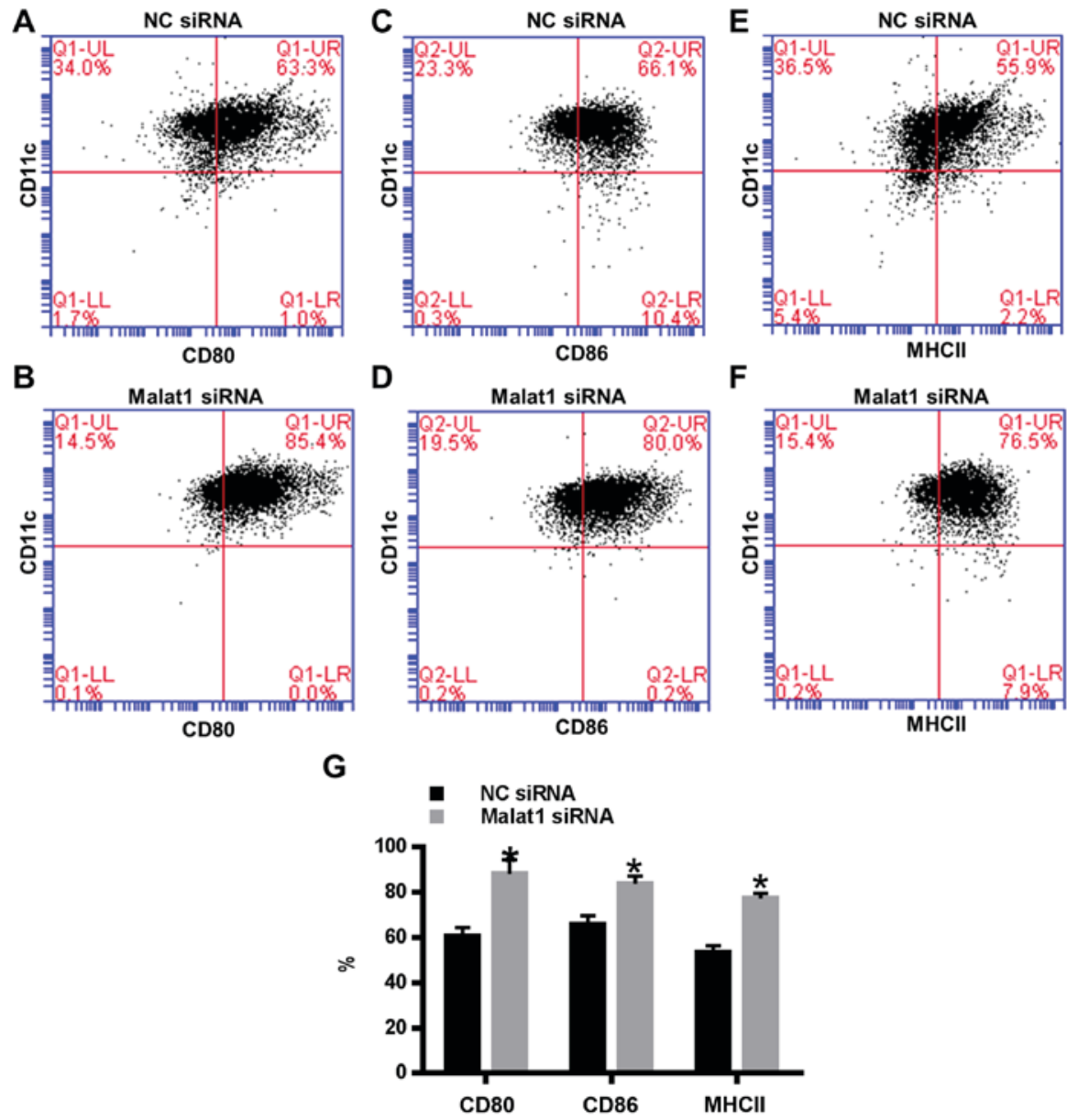

Figure 2. Effects of Malat1 on the maturation of AEC-treated DCs. AECs were transfected with NC siRNA or Malat1 siRNA and then cocultured with DCs for $72 \mathrm{~h}$. The costimulatory molecules (A and B) CD80, (C and D) CD86, and (E and F) MHCII in DCs were detected by FACS. (G) Relative mRNA levels of CD80, CD86, and MHCII in DCs were determined by real-time PCR ( $\mathrm{n}=5$, " $\mathrm{P}<0.05$ vs. 'NC siRNA' group). AEC, airway epithelial cells; DC, dendritic cell; Malat1, metastasis-associated lung adenocarcinoma transcript 1; PCR, polymerase chain reaction.
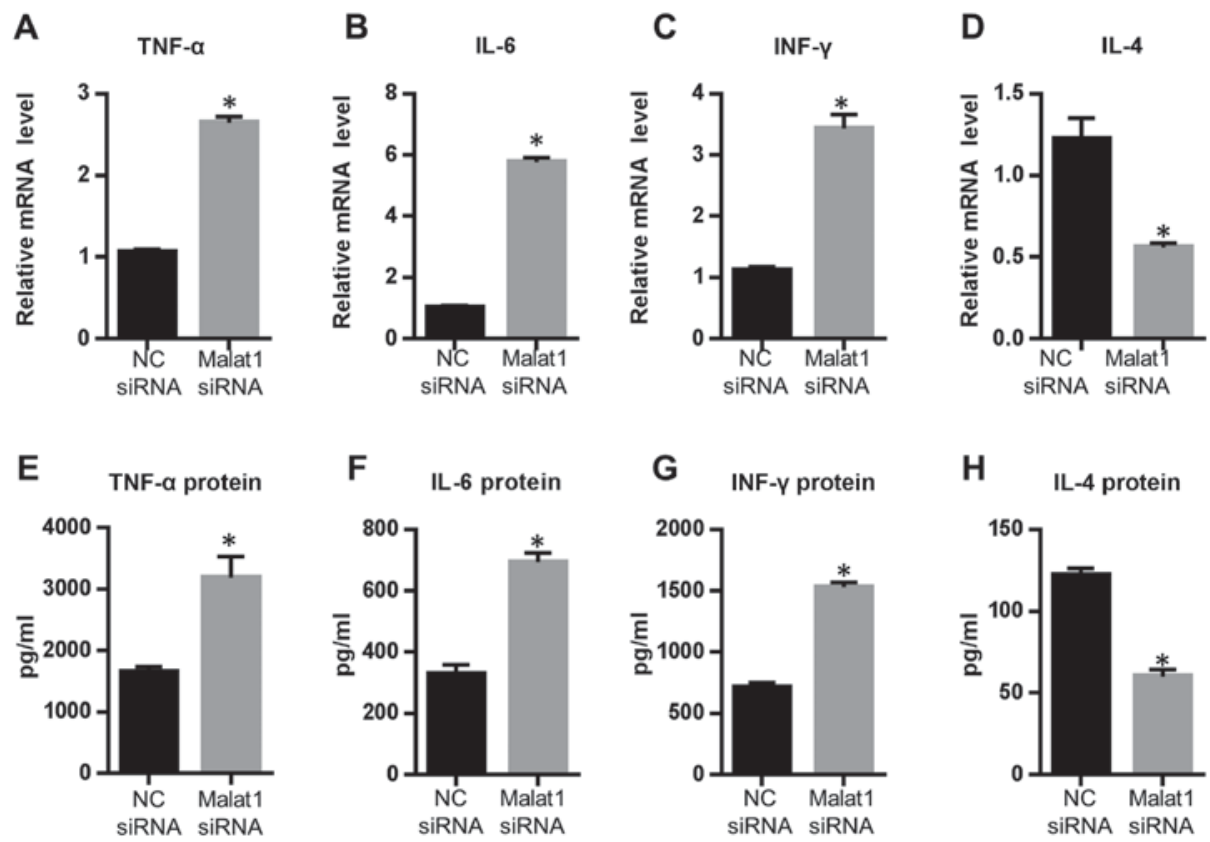

Figure 3. Effects of Malat1 on the inflammatory response of AEC-treated DCs. AECs were incubated in the presence of NC siRNA or Malat1 siRNA and then cocultured with DCs for further $72 \mathrm{~h}$. The expression of TNF- $\alpha$, IL-4, IL-6, and IFN-r in DCs were regulated after the suppression of Malat1. Relative mRNA levels of (A) TNF- $\alpha$, (B) IL-4, (C) IL-6, and (D) IFN-r detected by RT-qPCR. The protein levels of (E) TNF- $\alpha$, (F) IL-4, (G) IL-6, and (H) IFN-r were detected by ELISA. Mean \pm SD was obtained from five different experiments (" $\mathrm{P}<0.05$ vs. 'NC siRNA' group). AEC, airway epithelial cells; DC, dendritic cell; Malat1, metastasis-associated lung adenocarcinoma transcript 1; RT-qPCR, real-time quantitive polymerase chain reaction; TNF- $\alpha$, tumor necrosis factor- $\alpha$. 

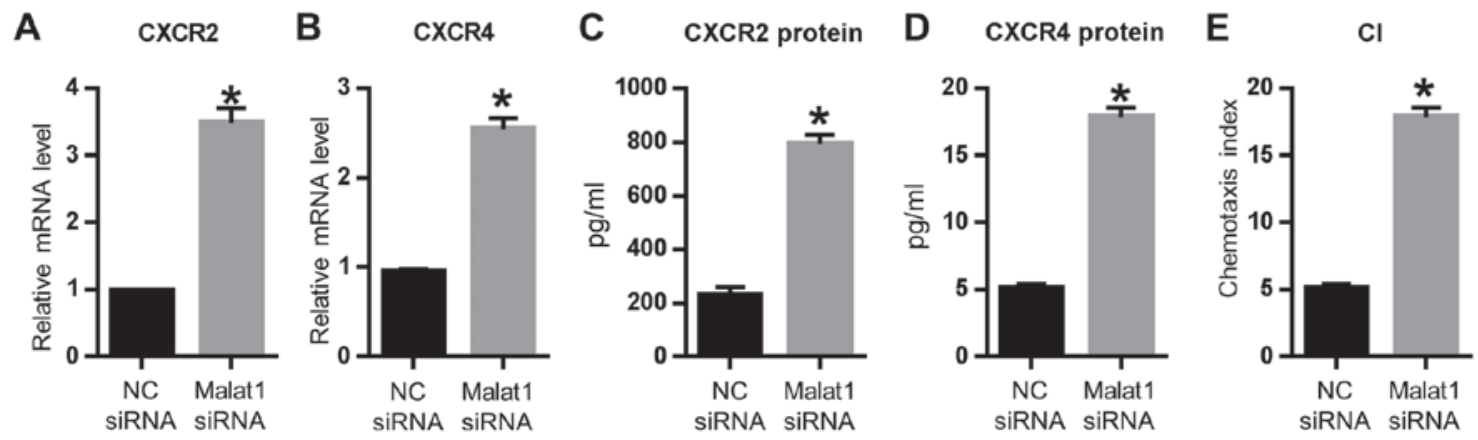

Figure 4. Effects of Malat1 on the chemokine expression of AEC-treated DCs. AECs were incubated in the presence of the NC siRNA or Malat1 siRNA and then cocultured with DCs for $72 \mathrm{~h}$. Relative mRNA level of (A) CXCR2 and (B) CXCR4 as detected by RT-qPCR. Relative protein level of (C) CXCR2 and (D) CXCR4 as detected by ELISA. (E) CI of the Transwell results. Mean \pm SD calculated from five different experiments ("P $<0.05$ vs. 'NC siRNA' group). CI, chemotaxis index; AEC, airway epithelial cells; DC, dendritic cell; Malat1, metastasis-associated lung adenocarcinoma transcript 1; RT-qPCR, real-time quantitive polymerase chain reaction.

A

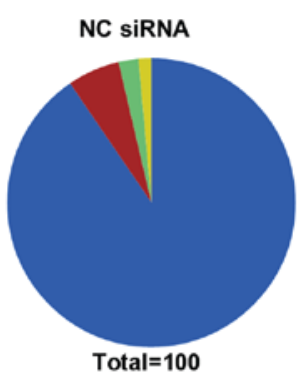

C

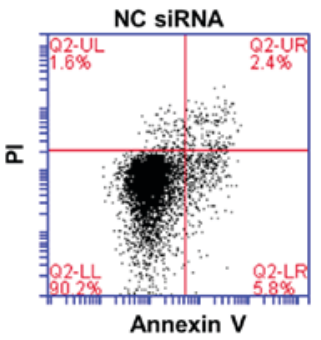

B

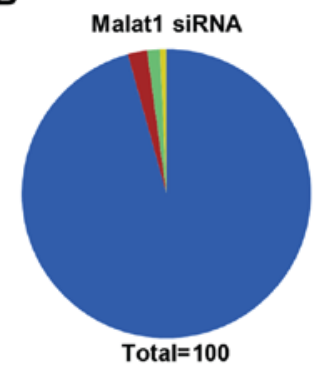

D

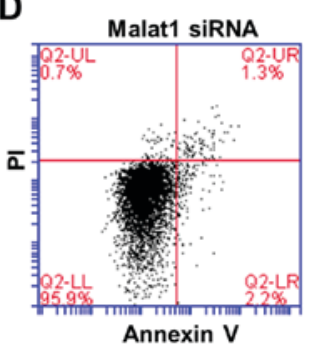

E

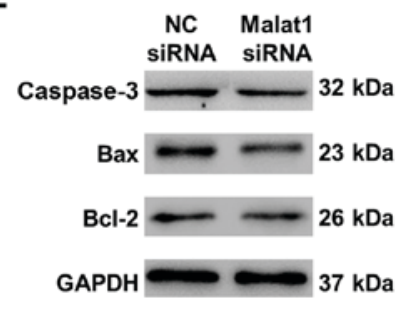

$\mathbf{F}$

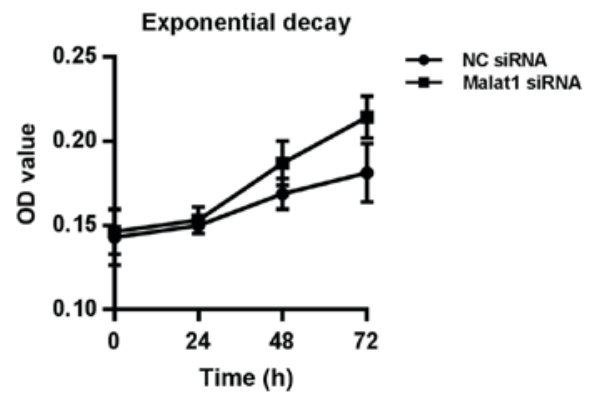

Figure 5. Effects of Malat1 on the apoptosis and proliferation of AEC-treated DCs. AECs were incubated with NC siRNA or Malat1 siRNA and then cocultured with DCs for $72 \mathrm{~h}$. The percentage of apoptosis of (A) NC siRNA and (B) Malat1 siRNA groups. FITC-Annexin-V of DCs was detected by FASC in (C) NC siRNA and (D) Malat1 siRNA groups. (E) Protein levels of caspase-3, Bax, and Bcl-2 in DCs were detected by WB. (F) DC cell viability was determined by MTT assay. Mean \pm SD calculated from five different experiments ( $\mathrm{P}<0.05$ vs. 'NC siRNA' group). AEC, airway epithelial cells; $D C$, dendritic cell; Malat1, metastasis-associated lung adenocarcinoma transcript 1.

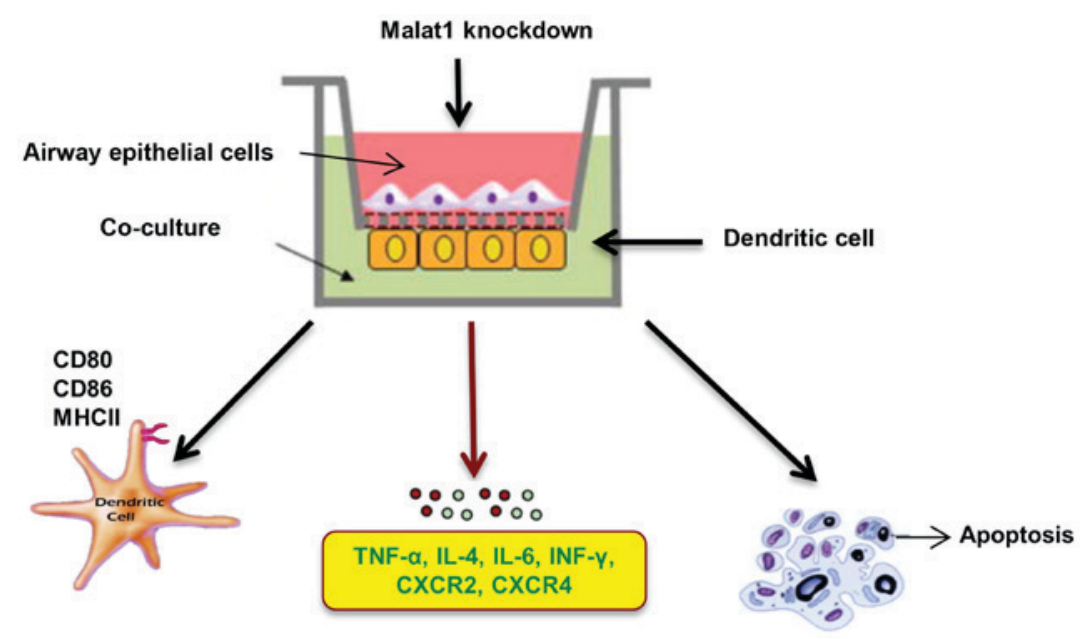

Figure 6. Schematic of the functional role of Malat1 in regulating AECs-treated DCs. AEC, airway epithelial cells; DC, dendritic cell; Malat1, metastasis-associated lung adenocarcinoma transcript 1. 
AECs, while the expression of membrane receptors CD40, CD209, and HLA-DR (data not shown) were unchanged. CD40, CD80, CD86, and HLA-DR have been reported to be downregulated by a specific lncRNA in DCs (8). Our results, at least, partly indicated that Malat1 can inhibit the maturation of AECs-conditioned DCs.

It was demonstrated that AECs could induce a tolerogenic phenotype of immune cells, including reduced $\mathrm{T}$ cell responsiveness $(2,3)$ and decreased pro-inflammatory cytokine production (3). In our study, we observed that the Malat1 knockdown could induce the secretion of the pro-inflammatory cytokines TNF- $\alpha$, IL-6, and IFN-r in AECs-conditioned DCs. However, the Malat1 siRNA suppressed the secretion of IL-4, which is a canonical type 2 cytokine. IL- 4 can reduce the expression of $\mathrm{B} 1$ and $\mathrm{B} 2$ receptors, which are induced by either IL-1 $\beta$ or TNF- $\alpha$ (48). These evidences support the negative effect between IL-4 and other pro-inflammatory cytokines. Besides the effect of Malat1 on inflammatory cytokines, we also explored the role of this lncRNA in chemokine production in the AECs-DCs co-cultured system. Our finding confirmed that the Malat1 suppression can augment chemotaxis by inducing the secretion of CXCR2 and CXCR4. All the results implied that Malat1 plays a vital role in cytokine production in AECs-conditioned DCs.

The impact of Malat1 on cellular apoptosis seems to be disease-dependent. While one study showed that Malat1 promoted neuronal apoptosis by sponging miR-124 in Parkinson's disease (49), another study found that it suppressed apoptosis of retinal ganglion cells in glaucoma through the PI3K/Akt signaling pathway (50). Another study (51) demonstrated that Malat1 shRNA plasmids enhanced apoptosis, weakened proliferation, and decreased migration and invasion of gallbladder cancer cells. We thus assessed the impact of Malat1 on the apoptosis and proliferation of AECs-conditioned DCs. As expected, Malat1 siRNA inhibited apoptosis and induced proliferation of AECs-conditioned DCs, confirming the pro-apototic role of Malat1 in the co-culture system.

Taken together, this is the first time to demonstrate the functional role of Malat1 in AECs-DCs co-culture system. That is, Malat1 induced the anti-inflammatory, alternatively inactivated phenotype and suppressed apoptosis in the microenvironment. We recognize a few limitations of our study, we did not explore the mechanism involved the Malat1 in AECs and DCs crosstalk, the future studies investigating the mechanism of Malat1 in the current model are still pending, such as microRNA sponge (49) and the potential signaling pathway as suggested by some previously studies (Stat3 and PI3K/Akt) (47,50). Through the emerging use of in vitro co-culture models, our study may help the understanding and uncovery of the complicated interplay between the respiratory epithelium and immune cells in airway disorders.

\section{Acknowledgements}

Not applicable.

\section{Funding}

The present study was supported by the Zhejiang Provincial Natural Science Foundation of China (grant no.LY17H010002),
National Natural Science Foundation of China (grant nos. 81770435,81700238 and 81400224), China Cardiovascular Association-Cardiac Rehabilitation and Metabolic Therapy Research Fund (grant no. CCA-CRMT-1614) and the Xinxin-Merck Cardiovascular Scientific Research Fund (grant no. 2017-CCA- Xinxin-Merck fund-004).

\section{Availability of data and materials}

The datasets used and/or analyzed during the current study are available from the corresponding author on reasonable request.

\section{Authors' contributions}

WW and TC designed the research; ZL, QZ, YW, FH and LG performed the research; ZL analyzed the data; and TC wrote the manuscript.

\section{Ethics approval and consent to participate}

Ethical approval for the study was granted from The First Affiliated Hospital of Zhejiang University (Hangzhou, China).

\section{Patient consent for publication}

Not applicable.

\section{Competing interests}

The authors declare that they have no competing interests.

\section{References}

1. Folkerts G and Nijkamp FP: Airway epithelium: More than just a barrier! Trends Pharmacol Sci 19: 334-341, 1998.

2. Mayer AK, Bartz H, Fey F, Schmidt LM and Dalpke AH Airway epithelial cells modify immune responses by inducing an anti-inflammatory microenvironment. Eur J Immunol 38: 1689-1699, 2008

3. Schmidt LM, Belvisi MG, Bode KA, Bauer J, Schmidt C, Suchy MT, Tsikas D, Scheuerer J, Lasitschka F, Gröne HJ and Dalpke AH: Bronchial epithelial cell-derived prostaglandin E2 dampens the reactivity of dendritic cells. J Immunol 186: 2095-2105, 2011.

4. Wissinger E, Goulding $\mathrm{J}$ and Hussell $\mathrm{T}$ : Immune homeostasis in the respiratory tract and its impact on heterologous infection. Semin Immunol 21: 147-155, 2009.

5. Holt PG, Strickland DH, Wikström ME and Jahnsen FL: Regulation of immunological homeostasis in the respiratory tract. Nat Rev Immunol 8: 142-152, 2008.

6. Mayer AK and Dalpke AH: Regulation of local immunity by airway epithelial cells. Arch Immunol Ther Exp (Warsz) 55: 353-362, 2007.

7. Castro-Garza J, King CH, Swords WE and Quinn FD: Demonstration of spread by Mycobacterium tuberculosis bacilli in A549 epithelial cell monolayers. FEMS Microbiol Lett 212: 145-149, 2002.

8. Sato K, Tomioka H, Shimizu T, Gonda T, Ota F and Sano C: Type II alveolar cells play roles in macrophage-mediated host innate resistance to pulmonary mycobacterial infections by producing proinflammatory cytokines. J Infect Dis 185: 1139-1147, 2002.

9. Sekiya T, Miyamasu M, Imanishi M, Yamada H, Nakajima T, Yamaguchi M, Fujisawa T, Pawankar R, Sano Y, Ohta K, et al: Inducible expression of a Th2-type CC chemokine thymus- and activation-regulated chemokine by human bronchial epithelial cells. J Immunol 165: 2205-2213, 2000. 
10. Soumelis V, Reche PA, Kanzler H, Yuan W, Edward G, Homey B, Gilliet M, Ho S, Antonenko S, Lauerma A, et al: Human epithelial cells trigger dendritic cell mediated allergic inflammation by producing TSLP. Nat Immunol 3: 673-680, 2002.

11. Iwata M, Hirakiyama A, Eshima Y, Kagechika H, Kato C and Song SY: Retinoic acid imprints gut-homing specificity on T cells. Immunity 21: 527-538, 2004.

12. Willart MA, Deswarte K, Pouliot P, Braun H, Beyaert R, Lambrecht BN and Hammad H: Interleukin-1 $\alpha$ controls allergic sensitization to inhaled house dust mite via the epithelial release of GM-CSF and IL-33. J Exp Med 209: 1505-1517, 2012.

13. Rimoldi M, Chieppa M, Salucci V, Avogadri F, Sonzogni A, Sampietro GM, Nespoli A, Viale G, Allavena P and Rescigno M: Intestinal immune homeostasis is regulated by the crosstalk between epithelial cells and dendritic cells. Nat Immunol 6 : 507-514, 2005

14. Jonuleit H, Schmitt E, Schuler G, Knop J and Enk AH: Induction of interleukin 10-producing, nonproliferating CD4(+) T cells with regulatory properties by repetitive stimulation with allogeneic immature human dendritic cells. J Exp Med 192: 1213-1222, 2000

15. Cech TR and Steitz JA: The noncoding RNA revolution-trashing old rules to forge new ones. Cell 157: 77-94, 2014.

16. Holoch D and Moazed D: RNA-mediated epigenetic regulation of gene expression. Nat Rev Genet 16: 71-84, 2015.

17. Zhang $\mathrm{Y}$ and Cao $\mathrm{X}$ : Long noncoding RNAs in innate immunity. Cell Mol Immunol 13: 138-147, 2016.

18. Heward JA and Lindsay MA: Long non-coding RNAs in the regulation of the immune response. Trends Immunol 35: 408-419, 2014

19. Wilusz JE, Sunwoo H and Spector DL: Long noncoding RNAs: Functional surprises from the RNA world. Genes Dev 23 . 1494-1504, 2009.

20. Berindan-Neagoe I, Monroig Pdel C, Pasculli B and Calin GA: MicroRNAome genome: A treasure for cancer diagnosis and therapy. CA Cancer J Clin 64: 311-336, 2014.

21. Schmidt LH, Spieker T, Koschmieder S, Schäffers S, Humberg J, Jungen D, Bulk E, Hascher A, Wittmer D, Marra A, et al: The long noncoding MALAT-1 RNA indicates a poor prognosis in non-small cell lung cancer and induces migration and tumor growth. J Thorac Oncol 6: 1984-1992, 2011.

22. Shen L, Chen L, Wang Y, Jiang X, Xia H and Zhuang Z: Long noncoding RNA MALAT1 promotes brain metastasis by inducing epithelial-mesenchymal transition in lung cancer. J Neuro-Oncol 121: pp101-108, 2015.

23. Lai MC, Yang Z, Zhou L, Zhu QQ, Xie HY, Zhang F, Wu LM, Chen LM and Zheng SS: Long non-coding RNA MALAT-1 overexpression predicts tumor recurrence of hepatocellular carcinoma after liver transplantation. Med Oncol 29: 1810-1816, 2012.

24. Zhang HM, Yang FQ, Chen SJ, Che J and Zheng JH: Upregulation of long non-coding RNA MALAT1 correlates with tumor progression and poor prognosis in clear cell renal cell carcinoma. Tumour Biol 36: 2947-2955, 2015.

25. Zheng HT, Shi DB, Wang YW, Li XX, Xu Y, Tripathi P, Gu WL, Cai GX and Cai SJ: High expression of lncRNA MALAT1 suggests a biomarker of poor prognosis in colorectal cancer. Int J Clin Exp Pathol 7: 3174-3181, 2014.

26. Okugawa Y, Toiyama Y, Hur K, Toden S, Saigusa S, Tanaka K, Inoue $\mathrm{Y}$, Mohri Y, Kusunoki M, Boland CR and Goel A: Metastasis-associated long non-coding RNA drives gastric cancer development and promotes peritoneal metastasis. Carcinogenesis 35: 2731-2739, 2014

27. Ellis MJ, Ding L, Shen D, Luo J, Suman VJ, Wallis JW, Van Tine BA, Hoog J, Goiffon RJ, Goldstein TC, et al: Whole-genome analysis informs breast cancer response to aromatase inhibition. Nature 486: 353-360, 2012.

28. Guo F, Li Y, Liu Y, Wang J, Li Y and Li G: Inhibition of metastasis-associated lung adenocarcinoma transcript 1 in CaSki human cervical cancer cells suppresses cell proliferation and invasion. Acta Biochim Biophys Sin (Shanghai) 42: 224-229, 2010.

29. Pang EJ, Yang R, Fu XB and Liu YF: Overexpression of long non-coding RNA MALAT1 is correlated with clinical progression and unfavorable prognosis in pancreatic cancer. Tumour Biol 36: 2403-2407, 2015

30. Ying L, Chen Q, Wang Y, Zhou Z, Huang Y and Qiu F: Upregulated MALAT-1 contributes to bladder cancer cell migration by inducing epithelial-to-mesenchymal transition. Mol Biosyst 8: 2289-2294, 2012.

31. Yamada K, Kano J, Tsunoda H, Yoshikawa H, Okubo C, Ishiyama $\mathrm{T}$ and Noguchi $\mathrm{M}$ : Phenotypic characterization of endometrial stromal sarcoma of the uterus. Cancer Sci 97: 106-112, 2006.
32. Ma KX, Wang HJ, Li XR, Li T, Su G, Yang P and Wu JW: Long noncoding RNA MALAT1 associates with the malignant status and poor prognosis in glioma. Tumour Biol 36: 3355-3359, 2015.

33. Gutschner T, Hämmerle M and Diederichs S: MALAT1-a paradigm for long noncoding RNA function in cancer. J Mol Med (Berl) 91: 791-801, 2013.

34. Bernard D, Prasanth KV, Tripathi V, Colasse S, Nakamura T, Xuan Z, Zhang MQ, Sedel F, Jourdren L, Coulpier F, et al: A long nuclear-retained non-coding RNA regulates synaptogenesis by modulating gene expression. EMBO J 29: 3082-3093, 2010.

35. Corti M, Brody AR and Harrison JH: Isolation and primary culture of murine alveolar type II cells. Am J Respir Cell Mol Biol 14: 309-315, 1996.

36. Nie W, Yan H, Li S, Zhang Y, Yu F, Zhu W, Fan F and Zhu J: Angiotensin-(1-7) enhances angiotensin II induced phosphorylation of ERK1/2 in mouse bone marrow-derived dendritic cells. Mol Immunol 46: 355-361, 2009.

37. Papazian D, Chhoden T, Arge M, Vorup-Jensen T, Nielsen CH, Lund K, Würtzen PA and Hansen S: Effect of polarization on airway epithelial conditioning of monocyte-derived dendritic cells. Am J Respir Cell Mol Biol 53: 368-377, 2015.

38. Livak KJ and Schmittgen TD: Analysis of relative gene expression data using real-time quantitative PCR and the 2(-Delta Delta C(T)) method. Methods 25: 402-408, 2001

39. Weitnauer M, Schmidt L, Ng Kuet Leong N, Muenchau S, Lasitschka F, Eckstein V, Hübner S, Tuckermann J and Dalpke AH: Bronchial epithelial cells induce alternatively activated dendritic cells dependent on glucocorticoid receptor signaling. J Immunol 193: 1475-1484, 2014.

40. Diamond G, Legarda D and Ryan LK: The innate immune response of the respiratory epithelium. Immunol Rev 173: 27-38, 2000.

41. Ranzani V, Rossetti G, Panzeri I, Arrigoni A, Bonnal RJ, Curti S, Gruarin P, Provasi E, Sugliano E, Marconi M, et al: The long intergenic noncoding RNA landscape of human lymphocytes highlights the regulation of T cell differentiation by linc-MAF-4. Nat Immunol 16: 318-325, 2015.

42. Dijkstra JM and Ballingall KT: Non-human lnc-DC orthologs encode Wdnm1-like protein. Version 2. F1000Res 3: 160, 2014.

43. Huang W, Thomas B, Flynn RA, Gavzy SJ, Wu L, Kim SV, Hall JA, Miraldi ER, Ng CP, Rigo F, et al: DDX5 and its associated lncRNA Rmrp modulate TH17 cell effector functions. Nature 528: 517-522, 2015.

44. Spurlock CF III, Tossberg JT, Guo Y, Collier SP, Crooke PS III and Aune TM: Expression and functions of long noncoding RNAs during human $\mathrm{T}$ helper cell differentiation. Nature Commun 6: 6932, 2015

45. Collier SP, Collins PL, Williams CL, Boothby MR and Aune TM: Cutting edge: Influence of Tmevpg1, a long intergenic noncoding RNA, on the expression of Ifng by Th1 cells. J Immunol 189: 2084-2088, 2012.

46. Wang Y, Zhong H, Xie X, Chen CY, Huang D, Shen L, Zhang H, Chen ZW and Zeng G: Long noncoding RNA derived from CD244 signaling epigenetically controls CD8+ T-cell immune responses in tuberculosis infection. Proc Natl Acad Sci USA 112: E3883-E3892, 2015.

47. Wang P, Xue Y, Han Y, Lin L, Wu C, Xu S, Jiang Z, Xu J, Liu Q and Cao X: The STAT3-binding long noncoding RNA lnc-DC controls human dendritic cell differentiation. Science 344: 310-313, 2014.

48. Souza PP, Brechter AB, Reis RI, Costa CA, Lundberg P and Lerner UH: IL-4 and IL-13 inhibit IL- $1 \beta$ and TNF- $\alpha$ induced kinin B1 and B2 receptors through a STAT6-dependent mechanism. Br J Pharmacol 169: 400-412, 2013.

49. Liu W, Zhang Q, Zhang J, Pan W, Zhao J and Xu Y: Long non-coding RNA MALAT1 contributes to cell apoptosis by sponging miR-124 in Parkinson disease. Cell Biosci 7: 19, 2017.

50. Li HB, You QS, Xu LX, Sun LX, Abdul Majid AS, Xia XB and Ji D: Long non-coding RNA-MALAT1 mediates retinal ganglion cell apoptosis through the PI3K/Akt signaling pathway in rats with glaucoma. Cell Physiol Biochem 43: 2117-2132, 2017.

51. Sun KK, Hu PP and Xu F: Prognostic significance of long non-coding RNA MALAT1 for predicting the recurrence and metastasis of gallbladder cancer and its effect on cell proliferation, migration, invasion, and apoptosis. J Cell Biochem 119: 3099-3110, 2018.

This work is licensed under a Creative Commons Attribution-NonCommercial-NoDerivatives 4.0 International (CC BY-NC-ND 4.0) License. 